\title{
The effects of L-type amino acid transporter 1 on milk protein synthesis in mammary glands of dairy cows
}

\author{
Ye Lin, ${ }^{*}+$ Xiaoyu Duan, ${ }^{*}$ He Lv, ${ }^{*}$ Yang Yang, ${ }^{*}$ Ying Liu, ${ }^{*}$ Xuejun Gao, ${ }^{*} \dagger$ and Xiaoming Hou* ${ }^{1}$ \\ ${ }^{*}$ College of Life Science, \\ †Key Laboratory of Dairy Science of Education Ministry, and \\ ¥Key Laboratory of Animal Cellular and Genetics Engineering of Heilongjiang Province, Northeast Agricultural University, Harbin 150030, China
}

\section{ABSTRACT}

The mammary gland requires the uptake of AA for milk protein synthesis during lactation. The L-type amino acid transporter 1 (LAT1, encoded by $S L C 7 A 5$ ), found in many different types of mammalian cells, is indispensable as a transporter of essential AA to maintain cell growth and protein synthesis. However, the function of LAT1 in regulating milk protein synthesis in the mammary gland of the dairy cow remains largely unknown. For the current study, we characterized the relationship between LAT1 expression and milk protein synthesis in lactating dairy cows and investigated whether the mammalian target of rapamycin complex 1 (mTORC1) signaling controls the expression of LAT1 in their mammary glands. We found that LAT1 and the heavy chain of its chaperone, $4 \mathrm{~F} 2$, were expressed in mammary tissues of lactating cows, with the expression levels of LAT1 and the 4F2 heavy chain being significantly greater in lactating mammary tissues with highmilk protein content (milk yield, $33.8 \pm 2.1 \mathrm{~kg} / \mathrm{d}$; milk protein concentration $>3 \%$, wt $/ \mathrm{vol}, ; \mathrm{n}=3$ ) than in tissues from cows with low-milk protein content (milk yield, $33.7 \pm 0.5 \mathrm{~kg} / \mathrm{d}$; milk protein concentration $<3 \%$, $\mathrm{wt} / \mathrm{vol} ; \mathrm{n}=3)$. Immunofluorescence staining of sectioned mammary tissues from cows with high and low milk protein content showed that LAT1 was located on the whole plasma membrane of alveolar epithelial cells, suggesting that LAT1 provides essential AA to the mammary gland. In cultured mammary epithelial cells from the dairy cows with high-milk protein content, knockdown of LAT1 expression decreased cell viability and $\beta$-casein expression; in contrast, overexpression of LAT1 had the opposite effect. Inhibition of mTORC1 by rapamycin attenuated the phosphorylation of molecules related to mTORC1 signaling and caused a marked decrease in LAT1 expression in the cultured

Received May 19, 2017.

Accepted October 12, 2017.

${ }^{1}$ Corresponding author: xiaominghou@126.com cells; expression of $\beta$-casein also decreased significantly. These results suggest that LAT1 is involved in milk protein synthesis in the mammary glands of lactating dairy cows and that the mTORC1 signaling pathway might be a control point for regulation of LAT1 expression, which could ultimately be used to alter milk protein synthesis.

Key words: mammary gland, LAT1, milk protein, mTORC1

\section{INTRODUCTION}

Milk, and especially its proteins, is an important source of nutrition for humans and other mammals (Huffman and Harper, 1999). Lactation requires a steady and sufficient supply of AA to maintain the necessary synthesis of milk proteins in mammary glands (Bequette et al., 1998). Amino acids move into cells via AA transporters; therefore, mammary epithelial cells must express transporters for the efficient uptake of AA.

Among the different AA transporters, system L, an $\mathrm{Na}^{+}$-independent AA transport system, is the major route for transport of large neutral AA (i.e., branched and aromatic AA), most of which are EAA (Fotiadis et al., 2013). Four system L isoforms are known: the Ltype amino acid transporters (LAT) 1, 2, 3, and 4, encoded by SLC7A5, SLC7A8, SLC43A1, and SLC43A2, respectively (Segawa et al., 1999; Babu et al., 2003; Bodoy et al., 2005). Among them, LAT1 is ubiquitously expressed in the plasma membrane of many cell types, including those of skeletal muscle, the intestine, and the placenta (Dave et al., 2004; Roos et al., 2009; Walker et al., 2014). L-Type amino acid transporter 1 is also expressed in rat and bovine mammary tissues (Finucane et al., 2008; Matsumoto et al., 2013); LAT1 forms a heterodimeric complex with the heavy chain of the $4 \mathrm{~F} 2$ antigen (4F2hc) via a disulfide bridge (Wagner et al., 2001). Recently, LAT1 was found to be the transportcompetent unit in the complex (Napolitano et al., 2015) with $4 \mathrm{~F} 2 \mathrm{hc}$, a type-II glycoprotein, which functions as a chaperone for LAT1, facilitating its stability and its 
translocation to the plasma membrane (Napolitano et al., 2015).

L-Type amino acid transporter 1 is an indispensable transporter of EAA, which are needed to maintain cell proliferation and protein synthesis (Hyde et al., 2003). In rat retinal endothelial cells, LAT1 provides EAA for the high-level synthesis of proteins necessary for the continuous growth and proliferation of retinal vessels (Matsuyama et al., 2012). In primary human trophoblast cells, LAT1 contributes to the uptake of leucine by system L (Gaccioli et al., 2015). Expression of LAT1 is also present in placental cells, suggesting that it provides the EAA used by the growing fetus (Gaccioli et al., 2015). In human umbilical vein endothelial cells, the inhibition of LAT1 by 2 -aminobicyclo-(2,2,1)-heptane-2-carboxylic acid substantially suppresses leucine uptake and proliferation (Hayashi et al., 2014). In addition, the relative expression of LAT1 is associated with lactation, as a progressive increase in LAT1 mRNA concentration occurs in the mammary glands of dairy cows as they begin to lactate (Finucane et al., 2008). However, the precise location of LAT1 and 4F2hc in the mammary tissues of dairy cows and the precise role of LAT1 in milk protein synthesis remain unclear.

The mammalian target of rapamycin (mTOR) is a serine-threonine protein kinase that functions in many types of cells, where it links growth-factor signaling with energy and nutrient levels to control cell growth and protein metabolism (Wullschleger et al., 2006; Jewell et al., 2013). Two mTOR complexes (mTORC) are known: mTORC1 and mTORC2 (Zoncu et al., 2011). Signaling by mTORC1, but not by mTORC2, can be inhibited by rapamycin (Zoncu et al., 2011). In the human placenta, mTORC1 affects the activity of system L (Roos et al., 2007); however, the specific role of mTORC1 signaling in the regulation of LAT1 expression in the mammary glands of lactating dairy cows remains to be established.

The objective of the study reported herein was to assess the expression pattern of LAT1 and $4 \mathrm{~F} 2 \mathrm{hc}$ in the mammary glands of lactating dairy cows that produced milk with substantially different amounts of milk protein in an attempt to further elucidate the role and possible importance of LAT1 and 4F2hc in lactating dairy cows. To meet these objectives, LAT1 and 4F2hc expression in the tissues of lactating dairy cows was investigated by quantitative real-time PCR (qPCR), Western blot, and immunofluorescence. The effects of LAT1 on cell viability and milk protein synthesis were investigated with the 3-(4,5-dimethylthiazol2-yl)-2,5-diphenyltetrazolium bromide (MTT) assay and Western blot, respectively, in cultured mammary epithelial cells from the cows with high milk protein content in which LAT1 expression had been knocked down or in which LAT1 was overexpressed. Considering the well-established and widely reported cellular effects of mTORC1 signaling involve regulation of protein translation, we also assessed whether mTORC1 signaling alters LAT1 expression in the cultured mammary epithelial cells.

\section{MATERIALS AND METHODS}

\section{Animals and Tissue Collection}

The Northeast Agricultural University Animal Care and Use Committee (Harbin, China) approved all procedures involving the dairy cows. The experimental setup, animal characteristics, and sampling procedures have been described (Hou et al., 2016). Briefly, the experiments used 6 lactating, nonpregnant Holstein cows (parity $=3$, calving at $\sim 52$ to 54 mo of age) with a similar genetic background during their third lactation period (90 DIM). All cows were in good health and had a SCC of $<50,000$ cells $/ \mathrm{mL}$. The 6 Holstein cows were selected from a dairy herd based on their milk components (assessed between d 70 and 90 of lactation); the 3 cows that produced milk with high milk protein content (milk yield $=33.9 \pm 2.1 \mathrm{~kg} / \mathrm{d}$; milk protein concentration $>3 \%$, wt/vol) were grouped together, and the other 3 cows that produced milk with low milk protein content (milk yield $=33.7 \pm 0.5$ $\mathrm{kg} / \mathrm{d}$; milk protein $<3 \%$, wt/vol) made up the second group. An ANOVA with a mixed model showed that the milk protein content in lactating cows with high milk protein content was significantly higher than cows with low milk protein content $(P<0.01)$. Cows were fed ad libitum a TMR, which consisted of alfalfa silage and concentrates. Water was available at all times. The ingredient and nutrient composition of the diet was as described (Hou et al., 2016).

The 6 cows were slaughtered at 90 DIM. Mammary tissue samples from the mid-region of the mammary glands were collected, snap frozen in liquid nitrogen, and stored at $-80^{\circ} \mathrm{C}$ for RNA and protein extraction or were mounted in cryoblocks with optimal cutting temperature compound for the immunofluorescence study. For cell culture, additional fresh tissue samples from the cows producing milk with high milk protein content were placed in sterilized tubes containing icecold Hanks' balanced salt solution (Life Technologies, Carlsbad, CA) and immediately transported to the laboratory.

\section{$q P C R$}

Total RNA from mammary tissues was used for qPCR analysis. Total RNA was extracted by TRIzol 
reagent (Life Technologies) according to standard protocols. The RNA concentrations were measured using a NanoDrop 2000c spectrophotometer (Thermo Fisher Scientific, Wilmington, DE). The integrity of the RNA was assessed by agarose gel electrophoresis, with the $28 \mathrm{~S}$ rRNA band being approximately twice as intense as the $18 \mathrm{~S}$ rRNA band. Purified RNA was reverse transcribed into cDNA using M-MLV reverse transcriptase (Life Technologies) and oligo-dT as the primer according to the manufacturer's instructions (Lin et al., 2016).

Primers for housekeeping and target genes were designed with Primer Premier 5.0 software (Premier Biosoft, Palo Alto, CA). The primers and the product sizes are shown in Table 1. For each sample, qPCR was performed in triplicate on an Applied Biosystems 7500 Real-time PCR system (Applied Biosystems, Foster City, CA). Reactions were carried out in the wells of a 96-well plate, each well containing $2 \mu \mathrm{L}$ of cDNA, $10 \mu \mathrm{L}$ of SYBR Premix Ex TaqII (TaKaRa, China, Dalian), $0.4 \mu \mathrm{L}$ of ROX Reference Dye II (TaKaRa), $0.8 \mu \mathrm{L}$ each of the forward and reverse primers, and $6 \mu \mathrm{L}$ of DNase/RNase-free water for a total volume of $20 \mu \mathrm{L}$. The amplification program consisted of an initial denaturation step at $95^{\circ} \mathrm{C}$ for $30 \mathrm{~s}$ and then 40 cycles involving denaturation at $95^{\circ} \mathrm{C}$ for $5 \mathrm{~s}$ followed by primer annealing-extension at $60^{\circ} \mathrm{C}$ for $34 \mathrm{~s}$, during which time fluorescence was measured. A melting curve was produced after completion of the PCR program to determine whether a gene-specific peak was present and a primer dimer was absent. The abundance of $\beta$-actin was not found to be significantly different among the cows; therefore, amplified $\beta$-actin from each sample was used to normalize the quantitative PCR data. The relative RNA expression levels were calculated by the $2^{-\Delta \mathrm{CT}}$ method (Schmittgen and Livak, 2008).

\section{Immunofluorescence}

Cryosections ( $8 \mu \mathrm{m}$ thick) of mammary gland tissues were fixed in cold acetone for $10 \mathrm{~min}$ at room tempera- ture. After 3 washes with PBS, sections were blocked for $1 \mathrm{~h}$ in $10 \%$ (vol/vol) goat serum in PBS for LAT1 detection or in $10 \%$ (vol/vol) rabbit serum in PBS for $4 \mathrm{~F} 2 \mathrm{hc}$ detection and then were incubated overnight at $4^{\circ} \mathrm{C}$ with rabbit polyclonal anti-LAT1 (1:50 dilution, Santa Cruz Biotechnology, Santa Cruz, CA) or goat polyclonal anti-4F2hc (1:50 dilution, Santa Cruz Biotechnology), respectively. After 3 washes with PBS, sections were incubated for $30 \mathrm{~min}$ at $37^{\circ} \mathrm{C}$ with fluorescein isothiocyanate-conjugated AffiniPure goat antirabbit IgG (1:50 dilution, ZSBG-Bio, Beijing, China) or fluorescein isothiocyanate-conjugated AffiniPure rabbit anti-goat IgG (1:50 dilution, ZSBG-Bio). Subsequently, sections were washed 3 times with PBS, counterstained with 4,6-diamidino-2-phenylindole (Beyotime Biotechnology, Shanghai, China) for $10 \mathrm{~min}$, and then mounted with Dabco (Air Products and Chemicals, Allentown, PA). Negative controls were processed in the same manner, with the exception that the primary antibody was absent. Fluorescence imaging was assessed by confocal microscopy (TCS SP2, Leica Microsystems GmbH, Wetzlar, Germany).

\section{Mammary Epithelial Cell Culture}

Mammary epithelial cells were isolated from lactating mammary parenchymal tissues of the 3 cows with high milk protein content by enzymatic digestion, as described (Hou et al., 2016). Briefly, minced mammary tissues were suspended in Dulbecco's modified Eagle's medium/Nutrient Mixture F-12 (Life Technologies) containing $100 \mathrm{U} / \mathrm{mL}$ of penicillin, $100 \mu \mathrm{g} / \mathrm{mL}$ of streptomycin, 10\% (vol/vol) fetal bovine serum (BI Biological Industries, Kibbutz Beit-Haemek, Israel), and $1 \mathrm{mg} / \mathrm{mL}$ of collagenase III (Solarbio, Beijing, China) at $37^{\circ} \mathrm{C}$ for $2 \mathrm{~h}$. The digest was filtered through a nylon mesh, and the filtrate was centrifuged at $150 \times$ $g$ for $10 \mathrm{~min}$ at room temperature. The cell pellet was then resuspended and seeded into Dulbecco's modified Eagle's medium/Nutrient Mixture F-12 supplemented

Table 1. Primer sequences used for quantitative real-time $\mathrm{PCR}^{1}$

\begin{tabular}{|c|c|c|c|}
\hline Gene & $\begin{array}{l}\text { GenBank accession } \\
\text { number }\end{array}$ & Primer sequence $\left(5^{\prime}\right.$ to $\left.3^{\prime}\right)$ & $\begin{array}{l}\text { Product } \\
\text { size }(b p)\end{array}$ \\
\hline$L A T 1$ & NM_174613.2 & $\begin{array}{l}\text { F: ACCCTCACTGGTGTTCACG } \\
\text { R: CTCCGGTTTCTGGTAGCG }\end{array}$ & 151 \\
\hline $4 F 2 h c$ & NM_001024488.2 & $\begin{array}{l}\text { F: CCGTGGTCATCATCGTGC } \\
\text { R: CGCTCCTTTAGGTCCGCTA }\end{array}$ & 154 \\
\hline$\beta$-actin & NM_173979 & $\begin{array}{l}\text { F: TGTTAGCTGCGTTACACCCT } \\
\text { R: CTGTCACCTTCACCGTTCC }\end{array}$ & 163 \\
\hline
\end{tabular}


with $10 \%$ (vol/vol) fetal bovine serum, $100 \mathrm{U} / \mathrm{mL}$ of penicillin, $100 \mu \mathrm{g} / \mathrm{mL}$ of streptomycin, and lactating hormones $(5 \mu \mathrm{g} / \mathrm{mL}$ of insulin, $1 \mu \mathrm{g} / \mathrm{mL}$ of prolactin, and $1 \mu \mathrm{g} / \mathrm{mL}$ of hydrocortisone; Sigma-Aldrich, St. Louis, MO) in a plastic cell culture dish coated with $0.5 \%$ (wt/vol) rat tail collagen (Sigma-Aldrich). Cells were incubated at $37^{\circ} \mathrm{C}$ under a $5 \% \mathrm{CO}_{2}$ atmosphere. After the primary cells reached $\sim 80 \%$ confluence, they were trypsinized in a trypsin-EDTA solution $(0.25 \%$, wt/vol; Life Technologies) and passaged. All experiments were conducted using cells not older than passage 10. Expression of cytokeratin 18 and $\beta-\mathrm{CN}$ was detected by immunofluorescence before experimentation to ensure that the cells were purified mammary epithelial cells and were capable of synthesizing milk proteins (Supplemental Figure S1; https://doi.org/10 .3168/jds.2017-13201).

To explore whether mTORC1 signaling participated in the regulation of LAT1 expression, the cells were grown in 6 -well plates $\left(2 \times 10^{5}\right.$ cells/well $)$ to $\sim 90 \%$ confluence and then were incubated with $100 \mathrm{n} M$ rapamycin or vehicle $[0.02 \%$ (vol $/ \mathrm{vol}$ ) dimethyl sulfoxide]. After a 24-h incubation, cells were collected for Western blot analysis.

\section{Plasmid Construction}

To construct the LAT1 expression plasmid, fulllength bovine $L A T 1$ was amplified from mammary tissue cDNA using PCR. The primer pairs were forward $=$ 5'-GAGCTCATGGCGGGCTCAGGCCCCAAG-3' and reverse $=5$-CCGCGGTTACGTCTCCTGGGGAACCACGTGC-3'. The PCR product was subcloned into pIRES2-EGFP at its $S a c$ I and SacII sites (TIANDZ, Beijing, China). The integrity of the plasmid DNA was verified by DNA sequencing.

\section{Transfection}

Transient transfection was performed in the cultured mammary epithelial cells using Lipofectamine 2000 (Life Technologies) as described (Lin et al., 2016). Briefly, for knockdown of LAT1 expression, cells $(1 \times$ $10^{6}$ cells/well) grown to $80 \%$ confluence in 6 -well plates were transfected with $3 \mu \mathrm{g}$ of a bovine LAT1-specific small interfering RNA (siRNA) or with a sequencescrambled siRNA, which served as the negative control. The sequence-specific siRNA (sense $=5^{\prime}$-GGAUCGAGCUGCUCAUCAUTT-3') was designed and synthesized by Gene Pharma Corp. (Shanghai, China), and the concentration used in transfection was optimized according to the manufacturer's instruction (Lin et al., 2016). The scrambled siRNA sense sequence was
5'-UUCUCCGAACGUGUCACGUTT-3'. For overexpression of $L A T 1$, cells in 6 -well plates were transfected with $3 \mu \mathrm{g}$ of pIRES2-EGFP-LAT1 or with an empty pIRES2-EGFP vector, which served as the negative control. All experiments were performed in triplicate.

\section{Cell Viability Assay}

Cell viability was determined by the MTT method, as described (Hou et al., 2016). Briefly, the mammary epithelial cells were plated into a 96-well plate at $10^{3}$ cells/well. After 24,48 , and $72 \mathrm{~h}$ of transfection, $10 \mu \mathrm{L}$ of MTT $(5 \mathrm{mg} / \mathrm{mL})$ was added into each well, and the reactions were incubated for $4 \mathrm{~h}$ at $37^{\circ} \mathrm{C}$. Then, $100 \mu \mathrm{L}$ of dimethyl sulfoxide was added to each well to dissolve the formazan that had formed, and the absorbance was measured at $570 \mathrm{~nm}$ using a microculture plate reader (GF-M2000, Shandong Gaomi Caihong Analytical Instruments Co. Ltd., Shandong, China). Experiments were performed in triplicate.

\section{Western Blots}

For Western blot analysis, mammary tissues or cultured mammary epithelial cells were lysed in RIPA buffer (Beyotime Biotechnology) containing $0.5 \mathrm{mM}$ phenylmethylsulfonyl fluoride (Beyotime Biotechnology), $5 \mu \mathrm{g} / \mathrm{mL}$ of aprotinin (Sigma-Aldrich), and 5 $\mu \mathrm{g} / \mathrm{mL}$ of leupeptin (Sigma-Aldrich) on ice. Lysates were centrifuged at $17,800 \times g$ for $10 \mathrm{~min}$ at $4^{\circ} \mathrm{C}$ to remove debris, and the concentrations of the supernatant proteins were determined by the bicinchoninic acid method. Aliquots of the lysates containing equal amounts of protein $(35 \mu \mathrm{g}$ ) were separated on $10 \%$ (wt/ vol) SDS-polyacrylamide gels and blotted onto nitrocellulose membranes, which were then incubated in blocking solution (Beyotime Biotechnology) for $1 \mathrm{~h}$ at room temperature. Membranes were incubated overnight at $4^{\circ} \mathrm{C}$ with antibodies against LAT1 (1:200 dilution), 4F2hc (1:200 dilution), mTOR (1:200 dilution, Santa Cruz Biotechnology), phospho-mTOR (1:400 dilution, Abcam, Cambridge, MA), P70S6K (1:250 dilution, Abcam), phospho-P70S6K (1:1000 dilution, Abcam), 4E-BP1 (1:200 dilution, Santa Cruz Biotechnology), phospho-4E-BP1 (1:200 dilution, Santa Cruz Biotechnology), $\beta$-CN (1:500 dilution, Bioss Antibodies, Beijing, China), or $\beta$-actin (1:1000 dilution, Cell Signaling Technology, Beverly, MA). Membranes were then washed with $0.1 \%$ (vol/vol) Tween 20 in Tris-buffered saline and then incubated with horseradish peroxidaseconjugated anti-goat IgG (1:500 dilution, ZSGB-BIO, Beijing, China) or horseradish peroxidase-conjugated anti-rabbit IgG (1:500 dilution, ZSGB-BIO), depend- 
ing on the primary antibody used, for $1 \mathrm{~h}$ at room temperature. Peroxidase activity was detected using an enhanced chemiluminescence detection system (Cell Signaling Technology). The integrated optical density of each band was quantified using Image-Pro Plus 6.0 software (Media Cybernetics, Inc., Warrendale, PA). Each sample was normalized to its $\beta$-actin content.

\section{Statistical Analyses}

Quantitative data are presented as the mean \pm standard error of the means. Statistics were performed using GraphPad Prism 6 software (GraphPad, La Jolla, $\mathrm{CA}$ ). For mRNA and protein expression of LAT1 and $4 \mathrm{~F} 2 \mathrm{hc}$ in the tissues of the lactating cows producing milk with different protein content, data were analyzed by ANOVA using a mixed model with the milk protein content as a fixed effect and the cows as a random effect. In analyzing the effect of knockdown of LAT1 expression or overexpression of LAT1 on cell viability, the 2-way ANOVA with repeated measurements was used. Bonferroni's multiple comparison test was used for post-ANOVA comparisons. In analyzing the effect of LAT1 knockdown or overexpression on $4 \mathrm{~F} 2 \mathrm{hc}$ and $\beta-\mathrm{CN}$ expression, and the effects of rapamycin treatment on mTORC1 signaling and LAT1 expression, a 2-tailed unpaired $t$-test was performed. Differences were considered significant at $P<0.05$.

\section{RESULTS}

\section{LAT1 Expression in the Lactating Mammary Glands of Dairy Cows}

To compare LAT1 expression in lactating cows producing milk with different protein content, mammary tissues were taken from the 2 groups of cows and the mRNA and protein levels of LAT1 and $4 \mathrm{~F} 2 \mathrm{hc}$ were measured by $\mathrm{qPCR}$ and Western blot, respectively. The LAT1 and $4 F 2 h c$ mRNA levels were significantly higher for cows with high milk protein content than in tissues from the cows with low milk protein content $(P<0.01$, Figures $1 \mathrm{~A}$ and B). Similarly, the Western blots showed that the LAT1 and $4 \mathrm{~F} 2 \mathrm{hc}$ levels were significantly higher for the cows with high milk protein content than for those with low milk protein content $(P$ $<0.01$, Figures $1 \mathrm{C}$ and $\mathrm{D})$.

Figure 2 shows representative confocal immunofluorescence images of LAT1 and 4F2hc in mammary tissues of the lactating cows. In the tissues from cows with low milk protein content, LAT1 and $4 \mathrm{~F} 2 \mathrm{hc}$ staining intensity was detected in the whole plasma membrane of epithelial cells; whereas in the tissues from the cows with high-milk protein, LAT1 and 4F2hc staining intensity was increased with targeting to plasma membrane but also with some intracellular signal (Figure $2 \mathrm{~A}$ and $\mathrm{B}$ ).

\section{Effect of LAT1 on Synthesis of Milk Proteins in the Mammary Epithelial Cells of Dairy Cows}

Given that LAT1 is more highly expressed in mammary tissues of lactating dairy cows with high milk protein content, we assessed whether LAT1 has a role in regulating cell growth and synthesis of milk proteins. Cultured mammary epithelial cells were treated with the LAT1-specific siRNA or the scrambled siRNA, which served as the negative control. The abundance of LAT1 was measured $24 \mathrm{~h}$ later. As shown in Figures $3 \mathrm{~A}$ and $\mathrm{B}$, LAT1 siRNA treatment resulted in a $\sim 50 \%$ knockdown of LAT1. The results from the MTT assay indicated that knockdown of LAT1 expression in the cultured mammary epithelial cells markedly decreased cell viability at 24,48 , and $72 \mathrm{~h}$ after transfection with the sense siRNA in comparison with the scrambled
A

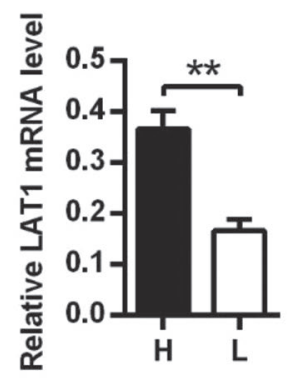

C

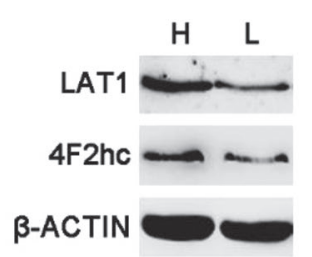

B

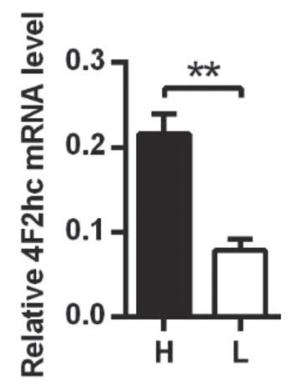

D

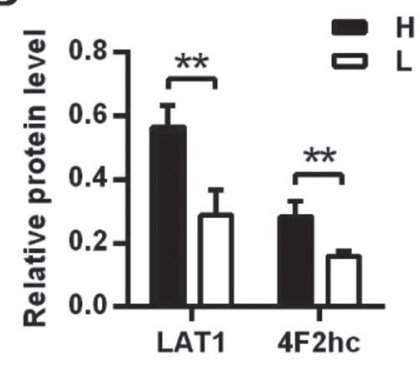

Figure 1. Expression of the L-type amino acid transporter 1 (LAT1) and the heavy chain of $4 \mathrm{~F} 2$ antigen (4F2hc) in mammary tissues of lactating dairy cows. Relative $L A T 1$ (A) and $4 F 2 h c(\mathrm{~B}) \mathrm{mRNA}$ levels in the mammary tissues of the lactating dairy cows as determined by quantitative real-time PCR. (C) Representative Western blot showing LAT1 and 4F2hc from lysates of mammary gland tissues from lactating dairy cows. $\beta$-actin served as the loading control. (D) Quantification of LAT1 and 4F2hc expression from Western blots as shown in Figure $1 \mathrm{C} . \mathrm{H}=$ lactating mammary tissues with high milk protein content; $\mathrm{L}=$ lactating mammary tissues with low milk protein content. Results are the mean \pm SEM; $\mathrm{n}=3$. ${ }^{* *} P<0.01$. 
siRNA $(P<0.01$; Figure $3 \mathrm{C})$. Next, we assessed the effects of knockdown of LAT1 expression on $4 \mathrm{~F} 2 \mathrm{hc}$ and $\beta-\mathrm{CN}$ expression $24 \mathrm{~h}$ after transfection. As shown in Figures 3D and E, knockdown of LAT1 expression in the cells led to a significantly decreased expression of $\beta$-CN $(P<0.05)$, but not of 4F2hc $(P>0.05)$.

Next, we evaluated the effect of LAT1 overexpression on mammary epithelial cell viability and synthesis of milk proteins in the cultured mammary epithelial cells. The cells were transfected with pIRES2-EGFP-LAT1 or an empty pIRES2-EGFP vector (negative control). As shown in Figures $4 \mathrm{~A}$ and $\mathrm{B}$, cells transfected with

A

Con

LAT1
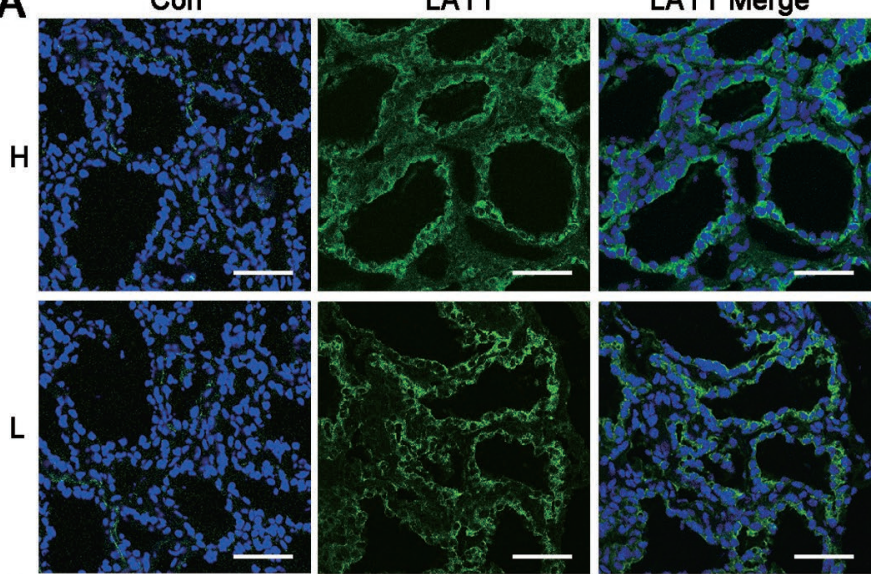

B

Con
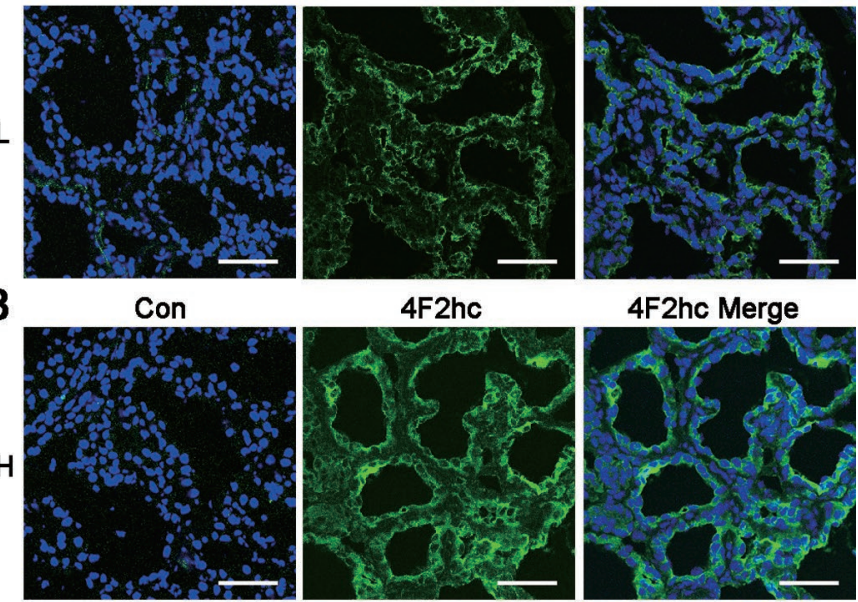

4F2hc Merge
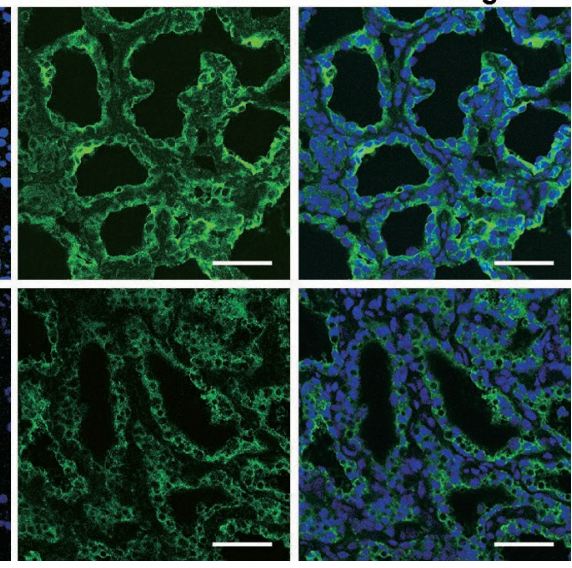

Figure 2. Localization of the L-type amino acid transporter 1 (LAT1) and the heavy chain of $4 \mathrm{~F} 2$ antigen ( $4 \mathrm{~F} 2 \mathrm{hc}$ ) in the mammary tissues of lactating dairy cows. (A) Immunofluorescence staining showed the location of LAT1 (green, labeled by fluorescein isothiocyanate; light gray in the grayscale version) and (B) $4 \mathrm{~F} 2 \mathrm{hc}$ (green, labeled by fluorescein isothiocyanate; light gray in the grayscale version). Nuclei were labeled with 4,6-diamidino-2-phenylindole (blue; dark gray in the grayscale version). Merged images show the overlap of stained nuclei and stained LAT1 or $4 \mathrm{~F} 2 \mathrm{hc} . \mathrm{H}=$ lactating mammary tissues with high milk protein content; $\mathrm{L}=$ lactating mammary tissues with low milk protein content; Con $=$ control. Scale bar, $60 \mu \mathrm{m}$. Color version available online.
pIRES2-EGFP-LAT1 expressed significantly higher levels of LAT1 as compared with cells transfected with the empty pIRES2-EGFP $(P<0.01)$. Overexpression of $L A T 1$ resulted in a significant increase in cell viability (Figure $4 \mathrm{C}$ ) and $\beta-\mathrm{CN}$ expression $(P<0.05$, Figures $4 \mathrm{D}$ and $\mathrm{E}$ ). However, we observed no change in $4 \mathrm{~F} 2 \mathrm{hc}$ expression in cells transfected with pIRES2EGFP-LAT1 as compared with the cells transfected with an empty plasmid ( $P>0.05$, Figures $4 \mathrm{D}$ and $\mathrm{E})$.
A

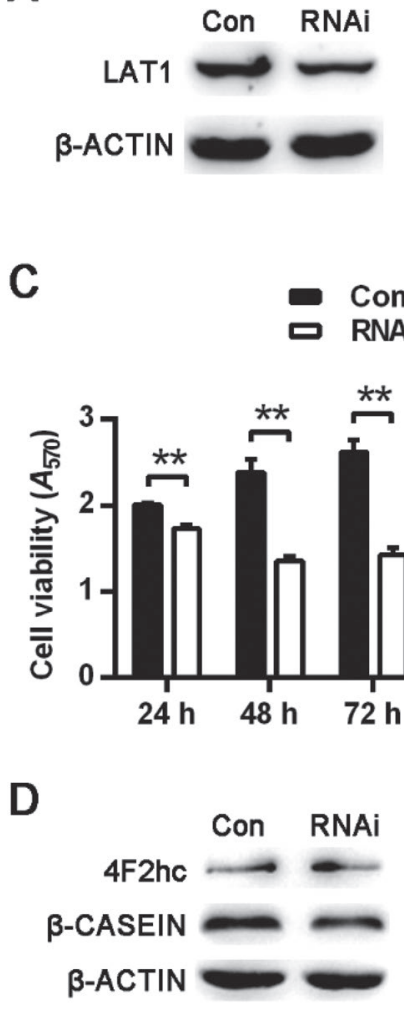

B

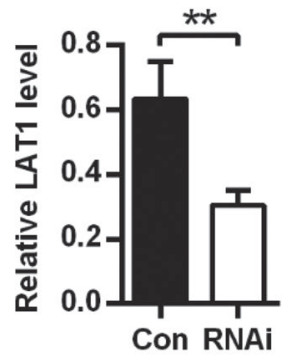

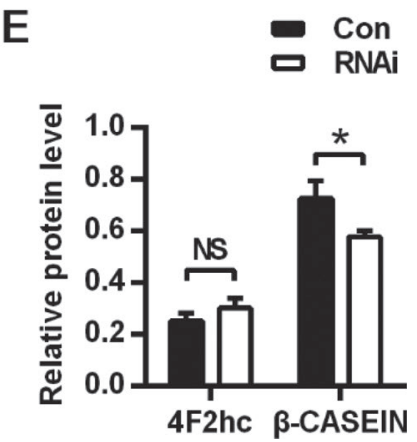

Figure 3. Effects of knockdown of L-type amino acid transporter 1 (LAT1) expression on cell viability and the synthesis of milk protein in dairy cows. (A) Representative Western blot showing the expression of LAT1 in mammary epithelial cells from lactating dairy cows after knockdown of $L A T 1$ expression by the small interfering RNA (RNAi). Samples of the cells were also exposed to a sequence-scrambled small interfering RNA (Con); $\beta$-actin served as the loading control. (B) Quantification of LAT1 expression from Western blots as shown in Figure 3A. (C) Viability of the mammary epithelial cells after knockdown of LAT1 expression by the small interfering RNA for 24, 48, and $72 \mathrm{~h}$. Samples of the cells were also exposed to a sequence-scrambled small interfering RNA (Con). (D) Representative Western blots showing expression of $4 \mathrm{~F} 2 \mathrm{hc}, \beta$-CN, and $\beta$-actin (loading control) in mammary epithelial cells exposed to the LAT1-specific small interfering RNA (RNAi) or the scrambled-sequence small interfering RNA (Con). (E) Quantification of $4 \mathrm{~F} 2 \mathrm{hc}$ and $\beta-\mathrm{CN}$ expression from Western blots as in Figure 3D. Results are the mean \pm SEM from 3 independent experiments. ${ }^{*} P<0.05 ;{ }^{*} P<0.01 ; \mathrm{NS}=$ not significantly different. 


\section{mTORC1 Signaling Regulates LAT1 Expression and Synthesis of Milk Proteins}

The mTORC1 signaling pathway is responsible for the stimulation of protein synthesis in the liver and muscle of growing animals (Kimball et al., 2000; O'Connor et al., 2003). To determine whether the mTORC1 signaling pathway participates in the regulation of LAT1 expression in the mammary glands of lactating dairy cows, we investigated the effects of mTORC1 inhibition upon phosphorylation of downstream mTORC1 substrates and LAT1 expression in the cultured mammary

A

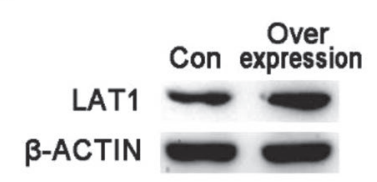

C Con
口 Overexpression

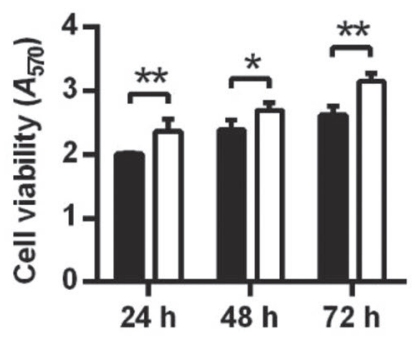

D

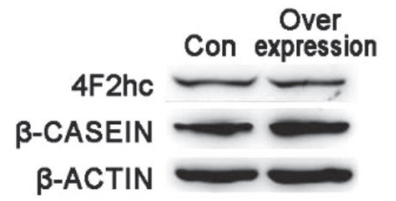

B

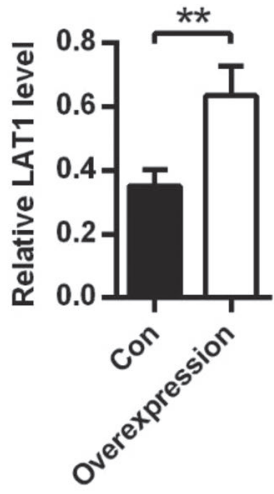

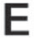

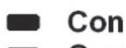

口 Overexpression

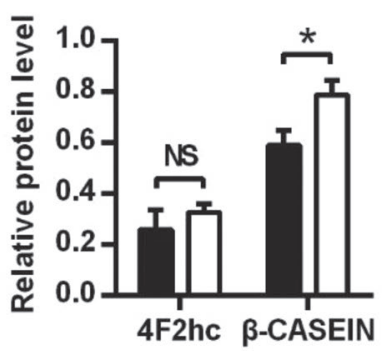

Figure 4. The effects of overexpression of the L-type amino acid transporter 1 (LAT1) on cell viability and milk protein synthesis. (A) Representative Western blots showing the expression of LAT1 and $\beta$-actin (loading control) in mammary epithelial cells overexpressing LAT1. (B) Quantification of LAT1 expression from Western blots as in Figure 4A. (C) Viability of mammary epithelial cells that overexpressed LAT1 24, 48, and $72 \mathrm{~h}$ after transfection with pIRES2-EGFPLAT1 or an empty pIRES2-EGFP vector (Con). (D) Representative Western blots showing the expression of $4 \mathrm{~F} 2 \mathrm{hc}, \beta-\mathrm{CN}$, and $\beta$-actin (loading control) in mammary epithelial cells overexpressing LAT1 $24 \mathrm{~h}$ after transfection with pIRES2-EGFP-LAT1. In the control group (Con), cells were transfected with an empty pIRES2-EGFP. (E) Quantification of $4 \mathrm{~F} 2 \mathrm{hc}$ and $\beta-\mathrm{CN}$ expression by integration of the bands shown in the Western blot of Figure 4D. Results are shown as the mean \pm SEM from 3 independent experiments. ${ }^{*} P<0.05 ;{ }^{* *} P<$ $0.01 ; \mathrm{NS}=$ not significantly different. epithelial cells. Cells were cultured with or without rapamycin $(100 \mathrm{n} M)$, which is an mTORC1-specific inhibitor, for $24 \mathrm{~h}$, and the phosphorylation states of components in the mTORC1 signaling pathway were measured by Western blot. As shown in Figures 5A and $\mathrm{B}$, incubation of the mammary epithelial cells with 100 $\mathrm{n} M$ rapamycin did not alter the expression of mTOR, P70S6K, and 4E-BP1, but it did significantly reduce phosphorylation of mTOR (at Ser2448; $P<0.01$ ) and its downstream effectors P70S6K (at Thr389; $P<0.05$ ) and 4E-BP1 (at Thr37/46; $P<0.05$ ). Thus, rapamycin treatment reduced activation of the mTORC1 signaling pathway in the cultured cells. Furthermore, inhibition of the mTORC1 signaling pathway by rapamycin caused a
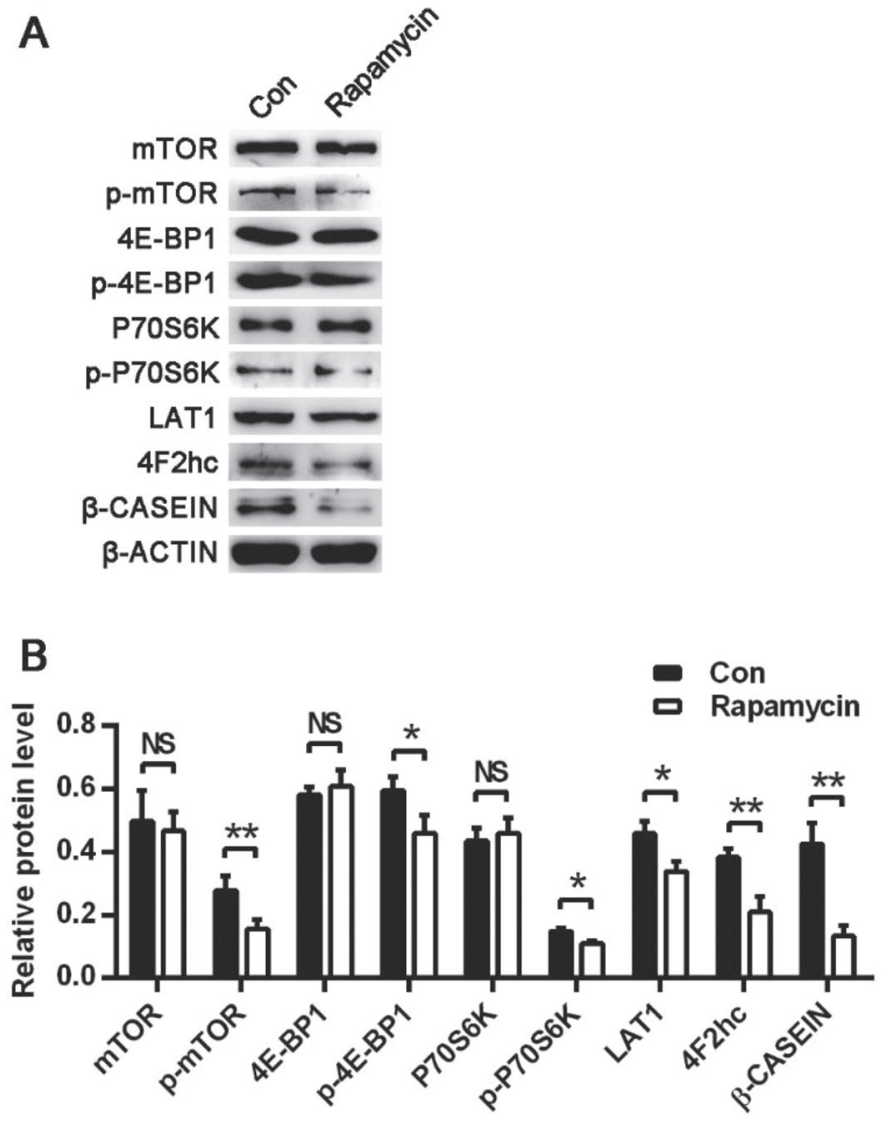

Figure 5. Effects of rapamycin on activation of mammalian target of rapamycin complex 1 (mTORC1) signaling on expression of the L-type amino acid transporter 1 (LAT1) in cultured mammary epithelial cells from dairy cows. (A) Representative Western blot showing the expression of the molecules related to mTORC1, LAT1, 4F2hc, and $\beta$-CN in rapamycin-treated mammary epithelial cells from dairy cows. (B) Quantification of the expression of the molecules from Western blots as in Figure 5A. Cells were cultured in the presence or absence (Con) of $100 \mathrm{n} M$ rapamycin for $24 \mathrm{~h}$; $\beta$-actin served as the loading control. The expression levels of each protein were normalized relative to that of $\beta$-actin. Results are the mean \pm SEM from 3 independent experiments. ${ }^{*} P<0.05 ;{ }^{*} P<0.01 ; \mathrm{NS}=$ not significantly different. 
marked decrease in the expression of LAT1 $(P<0.05)$, 4F2hc $(P<0.01)$, and $\beta$-CN $(P<0.01)$ in the cells as compared with untreated cells (Figures $5 \mathrm{~A}$ and $\mathrm{B}$ ).

\section{DISCUSSION}

During lactation, AA must be transported from the blood, across the basal membrane, and into mammary epithelial cells. L-Type amino acid transporter 1 is a $\mathrm{Na}^{+}$-independent transporter mediating cellular uptake of large EAA (Christensen, 1990). In our study, we showed that LAT1 expression is increased in lactating dairy cows with high milk protein content, suggesting that LAT1 expression is associated with lactation.

In rat mammary tissues, expression of LAT1 is greater than that of LAT2 during lactation (Matsumoto et al., 2013), indicating that LAT1 activity, which functions with $4 \mathrm{~F} 2 \mathrm{hc}$, is particularly relevant for lactation. We observed higher levels of mRNA and protein expression for LAT1 and 4F2hc in mammary tissues from lactating dairy cows with high milk protein content relative to the tissues from lactating cows with low milk protein content. Upregulating expression of LAT1 and 4F2hc may be beneficial if the increased amounts of LAT1 and $4 \mathrm{~F} 2 \mathrm{hc}$ provide the mammary epithelial cells with a sufficient amount of EAA for high levels of milk protein synthesis.

L-Type amino acid transporter 1 is ubiquitously expressed in many cell types and primarily functions within the plasma membrane (Walker et al., 2014). We observed that immunostaining for LAT1 is intense at the plasma membrane of alveolar epithelial cells in mammary tissues of lactating dairy cows. Moreover, LAT1 and 4F2he showed substantial overlap on the plasma membrane, indicating that the heterodimeric LAT1-4F2hc complex moves to the cell surface and potentiates large neutral AA transport into cells (Nakamura et al., 1999).

Because LAT1 expression is upregulated in the mammary tissues of lactating dairy cows with high milk protein content, LAT1 may be of particular importance for cell growth and the synthesis of milk proteins. We cultured mammary epithelial cells on the plastic culture plate coated with rat tail collagen to investigate the effects of LAT1 on the synthesis of milk proteins. Although some studies have reported that mammary epithelial cells cultured on an extracellular matrix-like scaffold could form an alveolar-like structure, which shows more natural and normal physiological properties (Hillreiner et al., 2017), mammary epithelial cell in a 2-dimensional monolayer culture still be used in studies on mammary gland physiology. The expression of $\alpha-$ and $\beta-\mathrm{CN}$ could be observed in bovine mammary epithelial cells cultured on plates coated with collagen, indicating that mammary epithelial cell in a 2-dimensional monolayer culture maintains milk protein gene expression (Rose et al., 2002; Hu et al., 2009). We observed that, in the cultured cells, inhibition of LAT1 expression by siRNA markedly decreased cell viability, whereas overexpression of LAT1 increased cell viability, suggesting that inhibition of LAT1 expression by siRNA decreases neutral AA incorporation into proteins in the cells and leads to suppression of cell growth and protein metabolism. These results are in agreement with previous studies that showed that, when LAT1 was overexpressed in mouse hepatocytes, transport activity of system L increased significantly and led to a growth advantage under conditions of limited amino acid availability (Campbell and Thompson, 2001). As expected, we found that increased cell viability is associated with increased $\beta$-CN expression in the mammary epithelial cells of dairy cows that overexpressed LAT1. This finding is consistent with a previous report showing that alterations in the expression and functions of AA transporters in humans are essential for the regulation in vivo of muscle protein synthesis after anabolic stimuli (Drummond et al., 2010). Overall, our data and previously reported data from studies that used species other than the cow support the hypothesis that LAT1 regulates milk protein synthesis in the mammary gland of the dairy cow. It could be a functional candidate gene for lactation traits.

Because we found changes in LAT1 expression associated with the synthesis of milk protein, identification of the signaling pathways regulating LAT1 expression may provide insight into the underlying molecular mechanisms that control milk yield and milk protein yield in dairy cows. Mammalian target of rapamycin complex 1 is an evolutionarily conserved multiprotein complex that coordinates a network of signaling cascades and functions as a key mediator of protein translation, gene transcription, and autophagy (Dodd and Tee, 2012). In vascular smooth muscle, LAT1 expression is upregulated by platelet-derived growth factor via its activation by mTORC1 signaling (Liu et al., 2004). In human placenta, mTORC1 has been shown to regulate LAT1 activity, thereby altering leucine uptake by placental cells (Roos et al., 2007). In primary human trophoblast cells, inhibition of mTORC1 decreases the activity of LAT1 and uptake of large EAA (Roos et al., 2009; Rosario et al., 2013). Treatment of murine T lymphocytes with rapamycin leads to downregulation of the expression of genes with protein products that participate in nutrient transport (Peng et al., 2002). We demonstrated that inhibition of mTORC1 by rapamycin decreased the phosphorylation levels of molecules related to mTORC1 signaling and caused a marked decrease in expression of LAT1 in cultured mammary 
epithelial cells. These decreases were accompanied by a significant decrease in the synthesis of the milk protein. These data are consistent with the recent report that human mTORC1 activation stimulates AA uptake and cell-surface expression of LAT1 in human trophoblast cells (Rosario et al., 2016).

\section{CONCLUSIONS}

We demonstrated that LAT1 expression is greater in the mammary tissues of lactating dairy cows with high milk protein content than with low milk-protein content, indicating an association between LAT1 expression and synthesis of milk proteins. Altering the mTORC1 signaling pathway may be a means of regulating LAT1 expression in the mammary glands of dairy cows, thereby controlling the synthesis of milk proteins.

\section{ACKNOWLEDGMENTS}

This work was supported by grants from the University Nursing Program for Young Scholars with Creative Talents in Heilongjiang Province (UNPYSCT-2015010, Harbin, China), the Young Talents Project of the Northeast Agricultural University (14QC03, Harbin, China), and the National Natural Science Foundation of China (Beijing; 31401109 to Y. L. and 31671285 to X. H.).

\section{REFERENCES}

Babu, E., Y. Kanai, A. Chairoungdua, D. K. Kim, Y. Iribe, S. Tangtrongsup, P. Jutabha, Y. Li, N. Ahmed, S. Sakamoto, N. Anzai, S. Nagamori, and H. Endou. 2003. Identification of a novel system $\mathrm{L}$ amino acid transporter structurally distinct from heterodimeric amino acid transporters. J. Biol. Chem. 278:43838-43845.

Bequette, B. J., F. R. Backwell, and L. A. Crompton. 1998. Current concepts of amino acid and protein metabolism in the mammary gland of the lactating ruminant. J. Dairy Sci. 81:2540-2559.

Bodoy, S., L. Martin, A. Zorzano, M. Palacin, R. Estevez, and J. Bertran. 2005. Identification of LAT4, a novel amino acid transporter with system L activity. J. Biol. Chem. 280:12002-12011.

Campbell, W. A., and N. L. Thompson. 2001. Overexpression of LAT1/CD98 light chain is sufficient to increase system L-amino acid transport activity in mouse hepatocytes but not fibroblasts. J. Biol. Chem. 276:16877-16884.

Christensen, H. N. 1990. Role of amino acid transport and countertransport in nutrition and metabolism. Physiol. Rev. 70:43-77.

Dave, M. H., N. Schulz, M. Zecevic, C. A. Wagner, and F. Verrey. 2004. Expression of heteromeric amino acid transporters along the murine intestine. J. Physiol. 558:597-610.

Dodd, K. M., and A. R. Tee. 2012. Leucine and mTORC1: A complex relationship. Am. J. Physiol. Endocrinol. Metab. 302:E1329E1342.

Drummond, M. J., E. L. Glynn, C. S. Fry, K. L. Timmerman, E. Volpi, and B. B. Rasmussen. 2010. An increase in essential amino acid availability upregulates amino acid transporter expression in human skeletal muscle. Am. J. Physiol. Endocrinol. Metab. 298:E1011-E1018.

Finucane, K. A., T. B. McFadden, J. P. Bond, J. J. Kennelly, and F. Q. Zhao. 2008. Onset of lactation in the bovine mammary gland:
Gene expression profiling indicates a strong inhibition of gene expression in cell proliferation. Funct. Integr. Genomics 8:251-264.

Fotiadis, D., Y. Kanai, and M. Palacin. 2013. The SLC3 and SLC7 families of amino acid transporters. Mol. Aspects Med. 34:139-158.

Gaccioli, F., I. L. Aye, S. Roos, S. Lager, V. I. Ramirez, Y. Kanai, T. L. Powell, and T. Jansson. 2015. Expression and functional characterisation of System L amino acid transporters in the human term placenta. Reprod. Biol. Endocrinol. 13:57.

Hayashi, K., P. Jutabha, T. Kamai, H. Endou, and N. Anzai. 2014. LAT1 is a central transporter of essential amino acids in human umbilical vein endothelial cells. J. Pharmacol. Sci. 124:511-513.

Hillreiner, M., N. I. Muller, H. M. Koch, C. Schmautz, B. Kuster, M. W. Pfaffl, and H. Kliem. 2017. Establishment of a 3D cell culture model of primary bovine mammary epithelial cells extracted from fresh milk. In Vitro Cell. Dev. Biol. Anim. https://doi.org/10 .1007/s11626-017-0169-7.

Hou, X., L. Lin, W. Xing, Y. Yang, X. Duan, Q. Li, X. Gao, and Y. Lin. 2016. Spleen tyrosine kinase regulates mammary epithelial cell proliferation in mammary glands of dairy cows. J. Dairy Sci. 99:3858-3868.

Hu, H., J. Wang, D. Bu, H. Wei, L. Zhou, F. Li, and J. J. Loor. 2009. In vitro culture and characterization of a mammary epithelial cell line from Chinese Holstein dairy cow. PLoS One 4:e7636.

Huffman, L. M., and W. J. Harper. 1999. Maximizing the value of milk through separation technologies. J. Dairy Sci. 82:2238-2244.

Hyde, R., P. M. Taylor, and H. S. Hundal. 2003. Amino acid transporters: Roles in amino acid sensing and signalling in animal cells. Biochem. J. 373:1-18.

Jewell, J. L., R. C. Russell, and K. L. Guan. 2013. Amino acid signalling upstream of mTOR. Nat. Rev. Mol. Cell Biol. 14:133-139.

Kimball, S. R., L. S. Jefferson, H. V. Nguyen, A. Suryawan, J. A. Bush, and T. A. Davis. 2000. Feeding stimulates protein synthesis in muscle and liver of neonatal pigs through an mTOR-dependent process. Am. J. Physiol. Endocrinol. Metab. 279:E1080-E1087.

Lin, Y., X. Sun, X. Hou, B. Qu, X. Gao, and Q. Li. 2016. Effects of glucose on lactose synthesis in mammary epithelial cells from dairy cow. BMC Vet. Res. 12:81.

Liu, X. M., S. V. Reyna, D. Ensenat, K. J. Peyton, H. Wang, A. I. Schafer, and W. Durante. 2004. Platelet-derived growth factor stimulates LAT1 gene expression in vascular smooth muscle: Role in cell growth. FASEB J. 18:768-770.

Matsumoto, T., E. Nakamura, H. Nakamura, M. Hirota, A. San Gabriel, K. Nakamura, N. Chotechuang, G. Wu, H. Uneyama, and K. Torii. 2013. Production of free glutamate in milk requires the leucine transporter LAT1. Am. J. Physiol. Cell Physiol. 305:C623C631.

Matsuyama, R., M. Tomi, S. Akanuma, A. Tabuchi, Y. Kubo, M. Tachikawa, and K. Hosoya. 2012. Up-regulation of L-type amino acid transporter 1 (LAT1) in cultured rat retinal capillary endothelial cells in response to glucose deprivation. Drug Metab. Pharmacokinet. 27:317-324.

Nakamura, E., M. Sato, H. Yang, F. Miyagawa, M. Harasaki, K. Tomita, S. Matsuoka, A. Noma, K. Iwai, and N. Minato. 1999. 4F2 (CD98) heavy chain is associated covalently with an amino acid transporter and controls intracellular trafficking and membrane topology of 4F2 heterodimer. J. Biol. Chem. 274:3009-3016.

Napolitano, L., M. Scalise, M. Galluccio, L. Pochini, L. M. Albanese, and C. Indiveri. 2015. LAT1 is the transport competent unit of the LAT1/CD98 heterodimeric amino acid transporter. Int. J. Biochem. Cell Biol. 67:25-33.

O'Connor, P. M., S. R. Kimball, A. Suryawan, J. A. Bush, H. V. Nguyen, L. S. Jefferson, and T. A. Davis. 2003. Regulation of translation initiation by insulin and amino acids in skeletal muscle of neonatal pigs. Am. J. Physiol. Endocrinol. Metab. 285:E40-E53.

Peng, T., T. R. Golub, and D. M. Sabatini. 2002. The immunosuppressant rapamycin mimics a starvation-like signal distinct from amino acid and glucose deprivation. Mol. Cell. Biol. 22:5575-5584.

Roos, S., N. Jansson, I. Palmberg, K. Saljo, T. L. Powell, and T. Jansson. 2007. Mammalian target of rapamycin in the human placenta regulates leucine transport and is down-regulated in restricted fetal growth. J. Physiol. 582:449-459. 
Roos, S., Y. Kanai, P. D. Prasad, T. L. Powell, and T. Jansson 2009. Regulation of placental amino acid transporter activity by mammalian target of rapamycin. Am. J. Physiol. Cell Physiol. 296:C142-C150.

Rosario, F. J., K. G. Dimasuay, Y. Kanai, T. L. Powell, and T. Jansson. 2016. Regulation of amino acid transporter trafficking by mTORC1 in primary human trophoblast cells is mediated by the ubiquitin ligase Nedd4-2. Clin. Sci. 130:499-512.

Rosario, F. J., Y. Kanai, T. L. Powell, and T. Jansson. 2013. Mammalian target of rapamycin signalling modulates amino acid uptake by regulating transporter cell surface abundance in primary human trophoblast cells. J. Physiol. 591:609-625.

Rose, M. T., H. Aso, S. Yonekura, T. Komatsu, A. Hagino, K. Ozutsumi, and Y. Obara. 2002. In vitro differentiation of a cloned bovine mammary epithelial cell. J. Dairy Res. 69:345-355.

Schmittgen, T. D., and K. J. Livak. 2008. Analyzing real-time PCR data by the comparative C(T) method. Nat. Protoc. 3:1101-1108.
Segawa, H., Y. Fukasawa, K. Miyamoto, E. Takeda, H. Endou, and Y. Kanai. 1999. Identification and functional characterization of a $\mathrm{Na}+$-independent neutral amino acid transporter with broad substrate selectivity. J. Biol. Chem. 274:19745-19751.

Wagner, C. A., F. Lang, and S. Broer. 2001. Function and structure of heterodimeric amino acid transporters. Am. J. Physiol. Cell Physiol. 281:C1077-C1093.

Walker, D. K., M. J. Drummond, J. M. Dickinson, M. S. Borack, K. Jennings, E. Volpi, and B. B. Rasmussen. 2014. Insulin increases mRNA abundance of the amino acid transporter SLC7A5/LAT1 via an mTORC1-dependent mechanism in skeletal muscle cells. Physiol. Rep. 2:e0238.

Wullschleger, S., R. Loewith, and M. N. Hall. 2006. TOR signaling in growth and metabolism. Cell 124:471-484.

Zoncu, R., A. Efeyan, and D. M. Sabatini. 2011. mTOR: From growth signal integration to cancer, diabetes and ageing. Nat. Rev. Mol. Cell Biol. 12:21-35. 